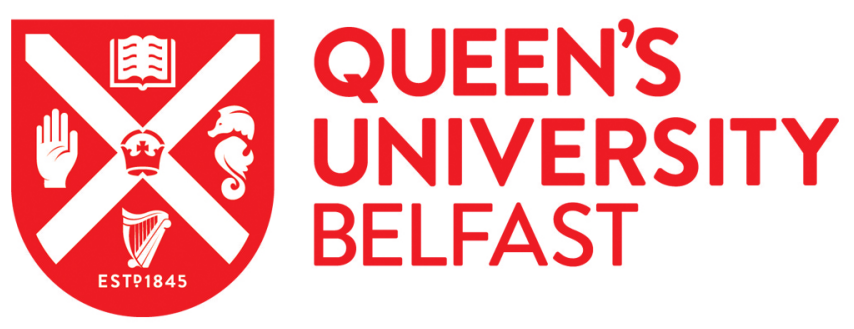

\title{
Unique Trapped Dimer State of the Photogenerated Hole in Hybrid Orthorhombic CH3NH3Pb/3 Perovskite: Identification, Origin, and Implications
}

Peng, C., Wang, J., Wang, H., \& Hu, P. (2017). Unique Trapped Dimer State of the Photogenerated Hole in Hybrid Orthorhombic CH3NH3Pbl3 Perovskite: Identification, Origin, and Implications. Nano Letters, 17(7), 7724-7730. https://doi.org/10.1021/acs.nanolett.7b03885

Published in:

Nano Letters

Document Version:

Peer reviewed version

Queen's University Belfast - Research Portal:

Link to publication record in Queen's University Belfast Research Portal

\section{Publisher rights}

Copyright 2017 American Chemical Society. This work is made available online in accordance with the publisher's policies. Please refer to any applicable terms of use of the publisher.

\section{General rights}

Copyright for the publications made accessible via the Queen's University Belfast Research Portal is retained by the author(s) and / or other copyright owners and it is a condition of accessing these publications that users recognise and abide by the legal requirements associated with these rights.

Take down policy

The Research Portal is Queen's institutional repository that provides access to Queen's research output. Every effort has been made to ensure that content in the Research Portal does not infringe any person's rights, or applicable UK laws. If you discover content in the Research Portal that you believe breaches copyright or violates any law, please contact openaccess@qub.ac.uk. 


\title{
Unique Trapped Dimer State of the Photogenerated Hole in the Hybrid Orthorhombic $\mathrm{CH}_{3} \mathrm{NH}_{3} \mathrm{PbI}_{3}$
}

\section{Perovskite: Identification, Origin and Implications}

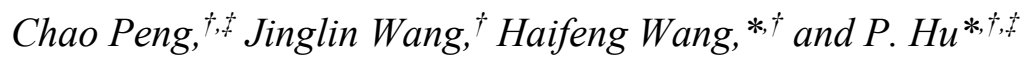 \\ ${ }^{\dagger}$ Key Laboratory for Advanced Materials, Center for Computational Chemistry and Research \\ Institute of Industrial Catalysis, School of Chemistry and Molecular Engineering, East China \\ University of Science and Technology, Shanghai 200237, P. R. China \\ * School of Chemistry and Chemical Engineering, Queen’s University Belfast, Belfast BT9 5AG, \\ UK \\ ABSTRACT: Revealing the innate character and transport of the photogenerated hole is essential \\ to boost the high photovoltaic performance in the lead-based organohalide perovskite. However, \\ knowledge at the atomic level is currently very limited. In this work, we systematically investigate \\ the properties of the photogenerated hole in the orthorhombic $\mathrm{CH}_{3} \mathrm{NH}_{3} \mathrm{PbI}_{3}$ using hybrid functional \\ PBE0 calculations with spin-orbit coupling included. An unexpected trapping state of the hole, \\ localized as $\mathrm{I}_{2}^{-}$(I dimer), is uncovered, which was never reported in photovoltaic materials. It is \\ shown that this localized configuration is energetically more favorable than that of the delocalized \\ hole state by $191 \mathrm{meV}$, and that it can highly promote the diffusion of the hole with an energy \\ barrier as low as $131 \mathrm{meV}$. Furthermore, the origin of I dimer formation upon trapping of the hole
}


is rationalized in terms of electronic and geometric effects and a good linear correlation is found between the hole trapping capacity and the accompanying structural deformation in $\mathrm{CH}_{3} \mathrm{NH}_{3} \mathrm{PbX} 3$ $(\mathrm{X}=\mathrm{Cl}, \mathrm{Br}$ and $\mathrm{I})$. It is demonstrated that good $\mathrm{CH}_{3} \mathrm{NH}_{3} \mathrm{PbX}_{3}$ materials for the hole diffusion should have small structural deformation energy and weak hole trapping capacity, which may facilitate the rational screening of superior photovoltaic perovskites.

KEYWORDS: lead-based organohalide perovskite, photogenerated hole, I dimer, photovoltaic

Organic-inorganic halide based perovskite materials such as $\mathrm{CH}_{3} \mathrm{NH}_{3} \mathrm{PbI}_{3}$, emerging as intriguing light harvesters in hybrid solid-state solar cells, have attracted considerable attention due to the tremendous power conversion efficiency (PCE) of over $20 \% .^{1-12}$ The high efficiency of perovskite can be attributed to the integrated merits of organic and inorganic semiconductors, including small and tunable band gap, low charge recombination rates, large optical absorption and high charge carrier mobility. ${ }^{6,7,13-21}$ In particular, the superior mobility and long diffusion lengths of charge carriers were reported to largely promise the high PCE.,22,23 With none hole transport layer, Etgar et al. reported a $\mathrm{PCE}$ of $5.5 \%$ in the meoscocopic $\mathrm{CH}_{3} \mathrm{NH}_{3} \mathrm{PbI}_{3} / \mathrm{TiO}_{2}$ heterojuntion solar cells, indicating the excellent hole transporting property of the $\mathrm{CH}_{3} \mathrm{NH}_{3} \mathrm{PbI}_{3}$ nanocrystals. ${ }^{5}$ By fitting the decay dynamics from the transient absorption (TA) spectroscopy, Xing and coworker found the hole diffusion length to be $110 \mathrm{~nm}$ in solution-processed $\mathrm{CH}_{3} \mathrm{NH}_{3} \mathrm{PbI}_{3}{ }^{7}$ Recently, the diffusion lengths for holes were even reported exceeding $175 \mu \mathrm{m}$ under 1 sun $\left(100 \mathrm{~mW} \mathrm{~cm}{ }^{-2}\right)$ in solution-grown $\mathrm{CH}_{3} \mathrm{NH}_{3} \mathrm{PbI}_{3}$ single crystals. ${ }^{23}$ These studies demonstrated the excellent hole transporting feature of the $\mathrm{CH}_{3} \mathrm{NH}_{3} \mathrm{PbI}_{3}$ perovskite and further research into this area is highly desirable. 
The formation of polaron quasiparticles is key to describe the trapping and migration behavior of the photogenerated electron and hole in photovoltaic materials, ${ }^{24,25}$ and can be used to investigate the photogenerated hole in $\mathrm{CH}_{3} \mathrm{NH}_{3} \mathrm{PbI}_{3}$. However, due to the crystal imperfection and small trapping energies of polaron, it is difficult to distinguish the trapping of a hole at defect sites and at perfect lattice sites in the $\mathrm{CH}_{3} \mathrm{NH}_{3} \mathrm{PbI}_{3}$ perovskite experimentally. ${ }^{26}$ Theoretically, despite some enlightening preliminary understandings of the photogenerated hole reported, the intrinsic property of the hole is still unknown. ${ }^{27-31}$ There are studies showing that the iodine defects in defective $\mathrm{CH}_{3} \mathrm{NH}_{3} \mathrm{PbI}_{3}$ perovskite introduce deep hole trapping level in the band gap, ${ }^{32-34}$ and the long lifetime of hole trapping by iodine interstitial defects can reduce the overall rate of electronhole recombination, which is beneficial for solar cell performance. ${ }^{32}$ However, the trapping character and diffusion behavior of photogenerated holes in pristine $\mathrm{CH}_{3} \mathrm{NH}_{3} \mathrm{PbI}_{3}$ are still to some extent missing and worth being identified. Recently, using the cluster models of $\mathrm{CsPbI}_{3}$ and $\mathrm{CH}_{3} \mathrm{NH}_{3} \mathrm{PbI}_{3}$, Neukirch et al. reported that the volumetric strain and $\mathrm{CH}_{3} \mathrm{NH}_{3}{ }^{+}$reorientation promoted the accumulation of space charge..$^{35}$ Due to the nonperiodic cluster model used that may have a finite size effect on the trapping behavior of the charge carrier, it is highly desirable to further obtain relevant understanding towards the trapping and transporting character of the photogenerated hole in the periodic $\mathrm{CH}_{3} \mathrm{NH}_{3} \mathrm{PbI}_{3}$ perovskite. In particular, the following questions need to be answered: (1) What is the trapping state of the photogenerated hole in the $\mathrm{CH}_{3} \mathrm{NH}_{3} \mathrm{PbI}_{3}$ perovskite? Or more specifically, is it localized or delocalized? (2) How does a hole diffuse in the materials? (3) Why does it possess the long diffusion length?

In this work, a first-principles study was carried out to explore the character of photogenerated holes in the orthorhombic $\mathrm{CH}_{3} \mathrm{NH}_{3} \mathrm{PbI}_{3}$ (ort- $\mathrm{CH}_{3} \mathrm{NH}_{3} \mathrm{PbI}_{3}$ ) perovskite, which is the most stable phase in $\mathrm{CH}_{3} \mathrm{NH}_{3} \mathrm{PbI}_{3}$ perovskite. Based on the results of high-precision hybrid density functional 
theory (DFT) calculations, we identified a new localized configuration of the photogenerated hole with a small polaron. More interestingly, the weak trapping capacity of this localized state was found to exhibit an excellent property for hole diffusion. This may explain the outstanding diffusion length of the hole in the $\mathrm{CH}_{3} \mathrm{NH}_{3} \mathrm{PbI}_{3}$ perovskite.

All the spin-polarized DFT calculations were performed using the Vienna ab-initio simulation package (VASP), unless otherwise specified. ${ }^{36-40}$ To correctly describe the electronic and geometric structure of $\mathrm{CH}_{3} \mathrm{NH}_{3} \mathrm{PbI}_{3}$, the spin-orbit coupling (SOC) together with the hybrid functional PBE0 ( $\alpha=0.188)$ was used. ${ }^{18-21,38,41-43}$ The project-augmented wave method was employed to describe the ion-electron interaction. ${ }^{44,45}$ The valence electronic states were expanded in plane-wave basis sets with an energy cutoff of $400 \mathrm{eV}$, and the force convergence criterion in structure optimization was set to be $0.05 \mathrm{eV} / \AA$. The $\mathrm{Pb} 6 \mathrm{~s}, 6 \mathrm{p}$ and $5 \mathrm{~d}$ orbitals, I $5 \mathrm{~s}$ and $5 \mathrm{p}$ orbitals, $\mathrm{C} 2 \mathrm{~s}$ and $2 \mathrm{p}$ orbitals, $\mathrm{N} 2 \mathrm{~s}$ and $2 \mathrm{p}$ orbitals, and the $\mathrm{H} 1 \mathrm{~s}$ orbital were treated as valence states. For the ort- $\mathrm{CH}_{3} \mathrm{NH}_{3} \mathrm{PbI}_{3}$, a supercell $(2 \times 1 \times 2)$ of $\mathrm{CH}_{3} \mathrm{NH}_{3} \mathrm{PbI}_{3}$ bulk $(\mathrm{a}=17.81 \AA, \mathrm{b}=12.82 \AA, \mathrm{c}=17.32$ $\AA$, and $\alpha=\beta=\gamma=90^{\circ}$ ) was constructed, ${ }^{18}$ containing $96 \mathrm{H}, 16 \mathrm{C}, 16 \mathrm{~N}, 48 \mathrm{I}$ and $16 \mathrm{~Pb}$ atoms. The $(1 \times 1 \times 1)$ grid was used for the $k$-point sampling of Brillouin zone during the structural optimization owing to the large bulk size, while the densities of states (DOS) were computed using a $(2 \times 2 \times 1)$ $k$-point mesh. The tests with more $k$-points and the higher energy cutoff of $500 \mathrm{eV}$ were carried out and verified the accuracy of the above settings (see Supporting Information). The transition states were located using a constrained optimization scheme. ${ }^{46-52}$ The DFT-D3 was carried out to describe the weak interaction in the organic-inorganic system..$^{53,54}$

Localization of the photogenerated hole. Firstly, we investigated the possibility of hole trapped in the periodic ort- $\mathrm{CH}_{3} \mathrm{NH}_{3} \mathrm{PbI}_{3}$ system. Considering that the valence band maximum (VBM) of the ort- $\mathrm{CH}_{3} \mathrm{NH}_{3} \mathrm{PbI}_{3}$ is constituted by I $5 \mathrm{p}$ and partly $\mathrm{Pb} 6$ s antibonding orbitals, ${ }^{18,38,41,55-}$ 
59 the inorganic $\mathrm{PbI}_{3}{ }^{-}$sublattice is extensively explored to identify the behavior of holes. In the presence of one photogenerated hole, the normal structural optimization gives rise to a delocalized state with spin density distributed over all I anions (see Figure 1a). Total density of state (TDOS) calculations show that there is no polaron peak of hole in the band gap (see Figure 1e), indicating a delocalized feature of the hole. To adequately identify the feature of the hole, we performed extensive configuration sampling using slight structural perturbation to break structural symmetry of ort- $\mathrm{CH}_{3} \mathrm{NH}_{3} \mathrm{PbI}_{3}$. Surprisingly, our calculations show that the hole can be trapped on two adjacent I anions, coupling to small lattice distortion. As illustrated in Figure 1b, the spin density accumulates evenly on the $\mathrm{p}$ orbitals of two adjacent $\mathrm{I}$ anions (noted as $\mathrm{I}^{1}$ and $\mathrm{I}^{2}$ ) with net spin of $0.47 \mu_{\mathrm{B}}$ and $0.46 \mu_{\mathrm{B}}$, respectively. The $\mathrm{Pb}-\mathrm{I}$ bonds, connected to these two I species, elongate from about 3.20 to $3.50 \AA$. From the density of state (DOS) in Figure 1f, it was found that a small sharp peak appears at the energy level of $0.75 \mathrm{eV}$ above the VBM. Performing the projected DOS (PDOS) of $\mathrm{I}^{1}$ and $\mathrm{I}^{2}$ species, we found that this unoccupied polaron peak primarily consists of the $5 p$ orbitals of $\mathrm{I}^{1}$ and $\mathrm{I}^{2}$ species (see Figure $\mathrm{S} 1$ ). Furthermore, our calculations exhibit considerable electron densities between the two I species of the hole-localized structure in contrast to the none electron density between them in the hole-delocalized structure (see Figure 1c and d). The I-I distance was also shortened to $3.33 \AA$ (versus the original $4.40 \AA$ ). Those verify a weak bond between the $\mathrm{I}^{1}$ and $\mathrm{I}^{2}$ anions. Therefore, we can see that the photogenerated hole is trapped as an $\mathrm{I}$ dimer $\left(\mathrm{I}_{2}^{-}\right)$in the ort- $\mathrm{CH}_{3} \mathrm{NH}_{3} \mathrm{PbI}_{3}$. In addition, we investigated how the I dimer formation is affected by the SOC and found that the effect is little (see Supporting Information). 


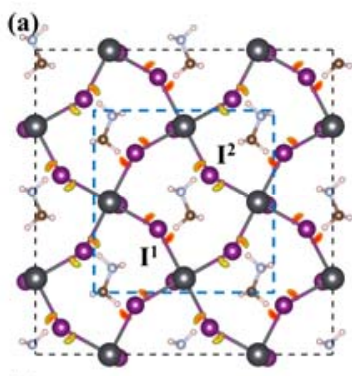

(b)

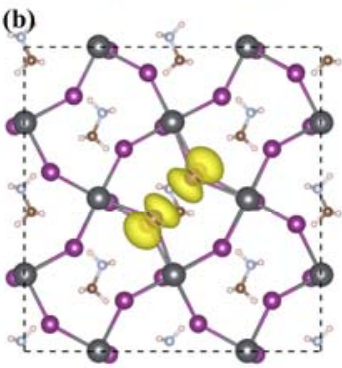

(c)

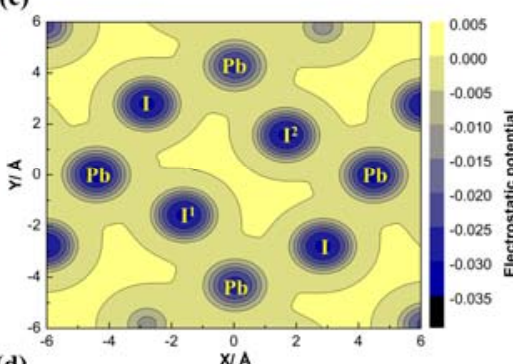

(d)

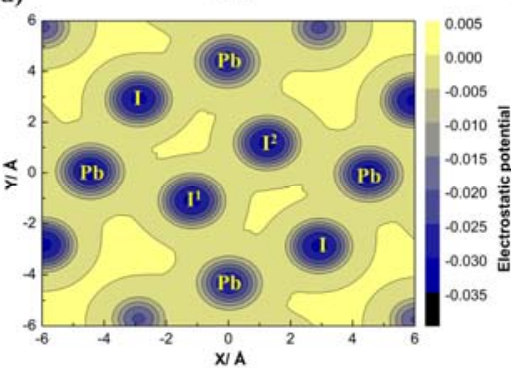

(e)

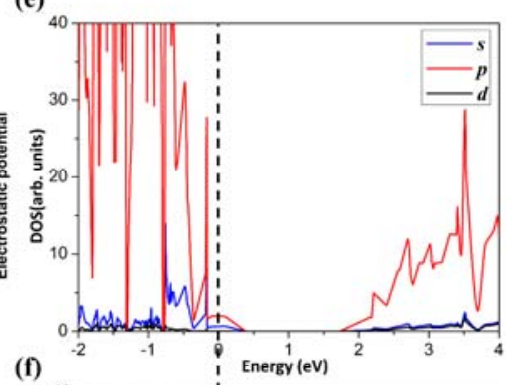

(f)

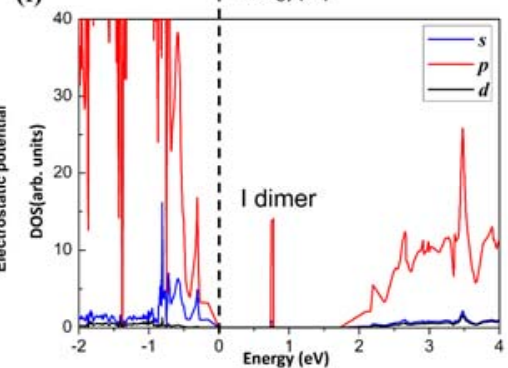

Figure 1. Different states with one hole introduced into the ort- $\mathrm{CH}_{3} \mathrm{NH}_{3} \mathrm{PbI}_{3}$ perovskite. The isosurface value is $0.0015 \mathrm{e} / \AA^{3}$. (a) is a delocalized state in which the hole delocalizes on all I anions. (b) is a localized state with the hole trapped on two equatorial I anions with an I dimer configuration. (c) $\sim(d)$ are the electrostatic potential diagrams corresponding to (a) and (b), respectively. The color bars represent the electrostatic potential of systems. The calculated area is the region selected in (a) with an internal blue block. The TDOS from the delocalized state and the hole-trapped state are shown in (e) and (f), respectively. In (a) and (b) the dark grey, purple, white, silver and brown balls represent $\mathrm{Pb}, \mathrm{I}, \mathrm{H}, \mathrm{N}$ and $\mathrm{C}$ atoms, respectively.

To quantitatively examine the I dimer, we evaluated the stability of the hole-trapped state. In our previous work, it was verified that hole trapping capacity (Ентс) can be used as a good descriptor to assess the stability of trapping states,${ }^{60}$ which is defined as the energy difference between the localized and delocalized states, i.e. $\mathrm{E}_{\mathrm{HTC}}=\mathrm{E}_{\text {localized }}-\mathrm{E}_{\text {delocalized. }}$ By calculating $\mathrm{E}_{\mathrm{HTC}}$, the localized state of the hole (I dimer configuration) in the ort- $\mathrm{CH}_{3} \mathrm{NH}_{3} \mathrm{PbI}_{3}$ was found to be more stable than the delocalized state by $-191 \mathrm{meV}$ (see Table 1), clearly suggesting that the hole is energetically 
favorable to be trapped as an I dimer. Furthermore, the weak trapping of I dimer also agrees with the near-band-edge optical responses of free carriers found in $\mathrm{CH}_{3} \mathrm{NH}_{3} \mathrm{PbI}_{3}$ in recent experiments. ${ }^{61}$

Table 1. The hole trapping capacities (Eнтc) in the presence of one hole in the ort- $\mathrm{CH}_{3} \mathrm{NH}_{3} \mathrm{PbI}_{3}$ perovskite. 1\#, 2\# and 3\# are the localized states of hole as I dimer-1, dimer-2 and dimer-3, respectively. Spin densities $\left(\mu_{\mathrm{B}}\right)$ of I anions from different states are also shown.

\begin{tabular}{cccc}
\hline \multirow{2}{*}{ States } & \multirow{2}{*}{$E_{\mathrm{HTC}} / \mathrm{meV}$} & \multicolumn{2}{c}{ Spin densities / $\mu \mathrm{B}$} \\
\cline { 3 - 4 } & & $\mathrm{I}^{1}$ & $\mathrm{I}^{2}$ \\
\hline $1 \#$ & -191 & 0.47 & 0.46 \\
$2 \#$ & -20 & 0.51 & 0.44 \\
$3 \#$ & 71 & 0.49 & 0.42 \\
delocalized & 0 & 0.01 & 0.01 \\
\hline
\end{tabular}

Enlightened by this finding, we systematically investigated other possible configurations of I dimers. Figure 2a shows the geometry of ort $-\mathrm{CH}_{3} \mathrm{NH}_{3} \mathrm{PbI}_{3}$ perovskite. It consists of a network of corner-shared $\left[\mathrm{PbI}_{6}\right]^{4-}$ octahedras with central $\mathrm{Pb}^{2+}$ cations, corner $\mathrm{I}^{-}$anions and occupied monovalent cations $\left(\mathrm{CH}_{3} \mathrm{NH}_{3}{ }^{+}\right)$in the cavities between octahedras. In each octahedral $\left[\mathrm{PbI}_{6}\right]^{4-}$ unit, two kinds of I anions are identified, named as equatorial I ( $\left.\mathrm{Ieq}^{-}\right)$and apical I ( $\left.\mathrm{Iap}^{-}\right)$anions. Upon trapping one hole coupled with structural relaxation, three classes of I dimer configurations can be found as illustrated in Figure 2a. I dimer-1: this I dimer forms via two adjacent $\mathrm{I}_{\mathrm{eq}}{ }^{-}$in two $\left[\mathrm{PbI}_{6}\right]^{4-}$ units (mentioned above, see Figure 1b). I dimer-2: the dimer consists of two adjacent $\mathrm{Ieq}_{\mathrm{eq}}$ in one $\left[\mathrm{PbI}_{6}\right]^{4-}$ unit (see Figure $2 \mathrm{~b}$ ). The spin densities on these two I anions are $0.51 \mu_{\mathrm{B}}$ and $0.44 \mu_{\mathrm{B}}$, respectively. I dimer-3: the hole localizes on the $\mathrm{Ieq}^{-}$and $\mathrm{Iap}^{-}$within the same $[\mathrm{PbI}]^{4-}$ octahedra (see Figure 2c). The spin densities on two anions are $0.49 \mu$ в and $0.42 \mu \mathrm{B}$, respectively. It was worth 
noting that the I dimer cannot form by two $\mathrm{Iap}^{-}$anions since $\mathrm{Iap}^{-}$anions point in the opposite directions. This kind of I dimer formation would result in a structural mismatch. Furthermore, the hole trapping capacities were calculated to examine the stabilities of these I dimers. In comparison with the Eнтc of dimer-1 (-191 meV), the Eнтс of dimer-2 and dimer-3 are -20 and $71 \mathrm{meV}$, respectively (see Table 1). I dimer-2 and dimer-3 are found to be less stable than I dimer-1, which can be rationalized as follows. For dimer-2, it results from the compression of two $\mathrm{Pb}-\mathrm{I}$ bonds. This induces small local distortion of the heavy $\mathrm{Pb}$ and I atoms thereby reducing structural stability. Regarding dimer-3, localization of the hole breaks the electrostatic attraction between the $\mathrm{Iap}^{-}$and $\mathrm{CH}_{3} \mathrm{NH}_{3}{ }^{+}$and induces large lattice distortion around $\mathrm{Iap}^{-}$and $\mathrm{Ieq}^{-}$anions, resulting in the decrease of the stability of system. Besides, we can also see that dimer- 1 and dimer-2 are more stable than the hole-delocalized state, indicating the favorable trapping of hole on the $\mathrm{Ieq}_{\mathrm{eq}}^{-}$. It is worth noting that the I dimer structure can also be found in the tetragonal phase of $\mathrm{CH}_{3} \mathrm{NH}_{3} \mathrm{PbI}_{3}$ perovskite at room-temperature; the molecular dynamics calculations at $300 \mathrm{~K}$ show that this $\mathrm{I}$ dimer-1 configuration is stable in this tetragonal system (see Supporting Information). In $\mathrm{CH}_{3} \mathrm{NH}_{3} \mathrm{PbI}_{3}$ perovskite, therefore, it may be a general character for the photogenerated hole localized as an I dimer configuration.
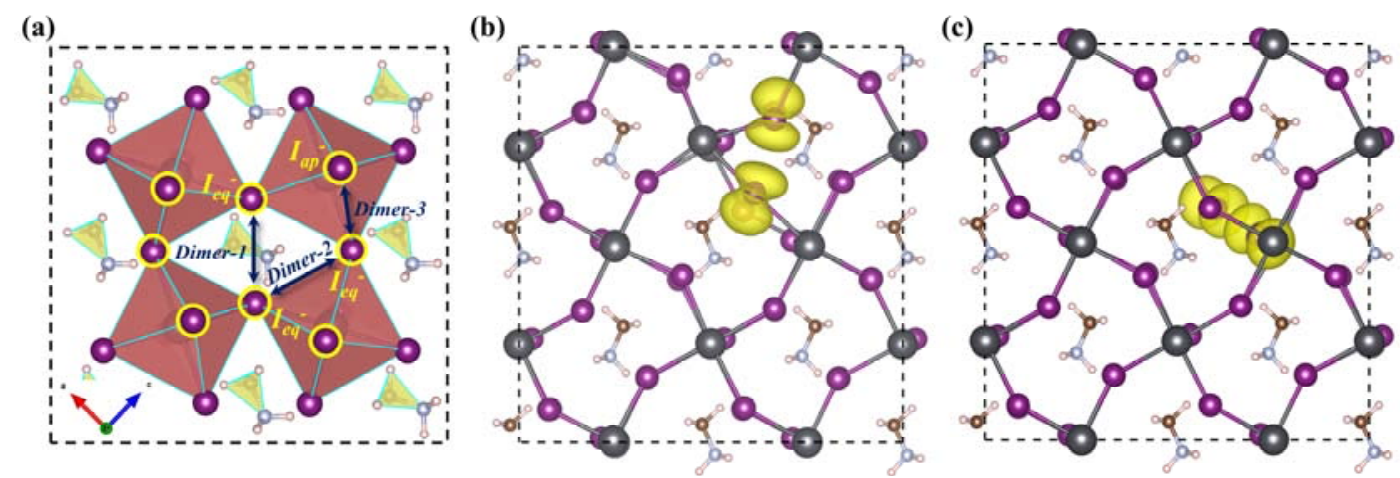

Figure 2. The geometrical structures and spin densities of the ort- $\mathrm{CH}_{3} \mathrm{NH}_{3} \mathrm{PbI}_{3}$ are illustrated in the presence of one hole. (a) is the top view of the orthorhombic phase of $\mathrm{CH}_{3} \mathrm{NH}_{3} \mathrm{PbI}_{3}$. $\mathrm{I}_{a p}{ }^{-}$and 
$\mathrm{I}_{\mathrm{eq}}{ }^{-}$represent the apical and the equatorial I anions, respectively. Three hole-trapped patterns of I dimers are also illustrated. Dimer-1, dimer-2 show hole trapping on both two $\mathrm{I}_{\mathrm{eq}}{ }^{-}$anions, while dimer-3 forms by hole trapped on one $\mathrm{Iap}^{-}$and one $\mathrm{Ieq}^{-}$. (b) illustrates the spin density of dimer-2 in which the hole localizes on two adjacent $\mathrm{I}_{\mathrm{eq}}{ }^{-}$anions. (c) illustrates that the hole localizes on the $\mathrm{I}_{\mathrm{ap}}{ }^{-}$ and $\mathrm{Ieq}^{-}$anions as dimer-3. The iso-surface level is $0.0015 \mathrm{e} / \AA^{3}$.

Hole diffusion. With this unexpected localization character of holes, we extended our investigation to the process of hole diffusion, aiming at understanding its long diffusion length. It is worth noting that there are some approaches to evaluate hole mobility such as calculating the effective mass. ${ }^{25,62}$ Here, considering that the hole is localized in the $\mathrm{I}_{2}{ }^{-}$configuration which accompanies an evident structure distortion, we proposed a hole hopping mechanism via the movement of I dimer configuration and examined its feasibility. Figure 3a shows three paths for hole diffusion via I dimers in ort- $\mathrm{CH}_{3} \mathrm{NH}_{3} \mathrm{PbI}_{3}$. Path 1 is a concerted mechanism (dimer- $1 \rightarrow$ dimer-1). As indicated by the black arrow in Figure 3c, this path describes the hole diffusion from one dimer- 1 configuration $\left(\mathrm{I}^{1} / \mathrm{I}^{2}\right)$ to another dimer- $1\left(\mathrm{I}^{3} / \mathrm{I}^{4}\right)$ along the $\mathrm{I}^{1}-\mathrm{I}^{2}$ direction via shifting the $\mathrm{I}^{2}$ toward $\mathrm{I}^{3}$. In the transition state (TS1), $\mathrm{I}^{1}, \mathrm{I}^{2}$ and $\mathrm{I}^{3}$ are approximately in a line with the bond lengths of $\mathrm{I}^{2}-\mathrm{I}^{3}$ shortened $(3.71 \AA)$ and $\mathrm{I}^{1}-\mathrm{I}^{2}$ stretched $(4.48 \AA)$, while the distance between $\mathrm{I}^{3}$ and $\mathrm{I}^{4}$ is close to $4.17 \AA$. Electronically, the hole localizes around I anions with low spin densities on the $\mathrm{I}^{1}(0.02 \mu \mathrm{B}), \mathrm{I}^{2}(0.04 \mu \mathrm{B}), \mathrm{I}^{3}(0.03 \mu \mathrm{B})$ and $\mathrm{I}^{4}(0.04 \mu \mathrm{B})$, respectively. 

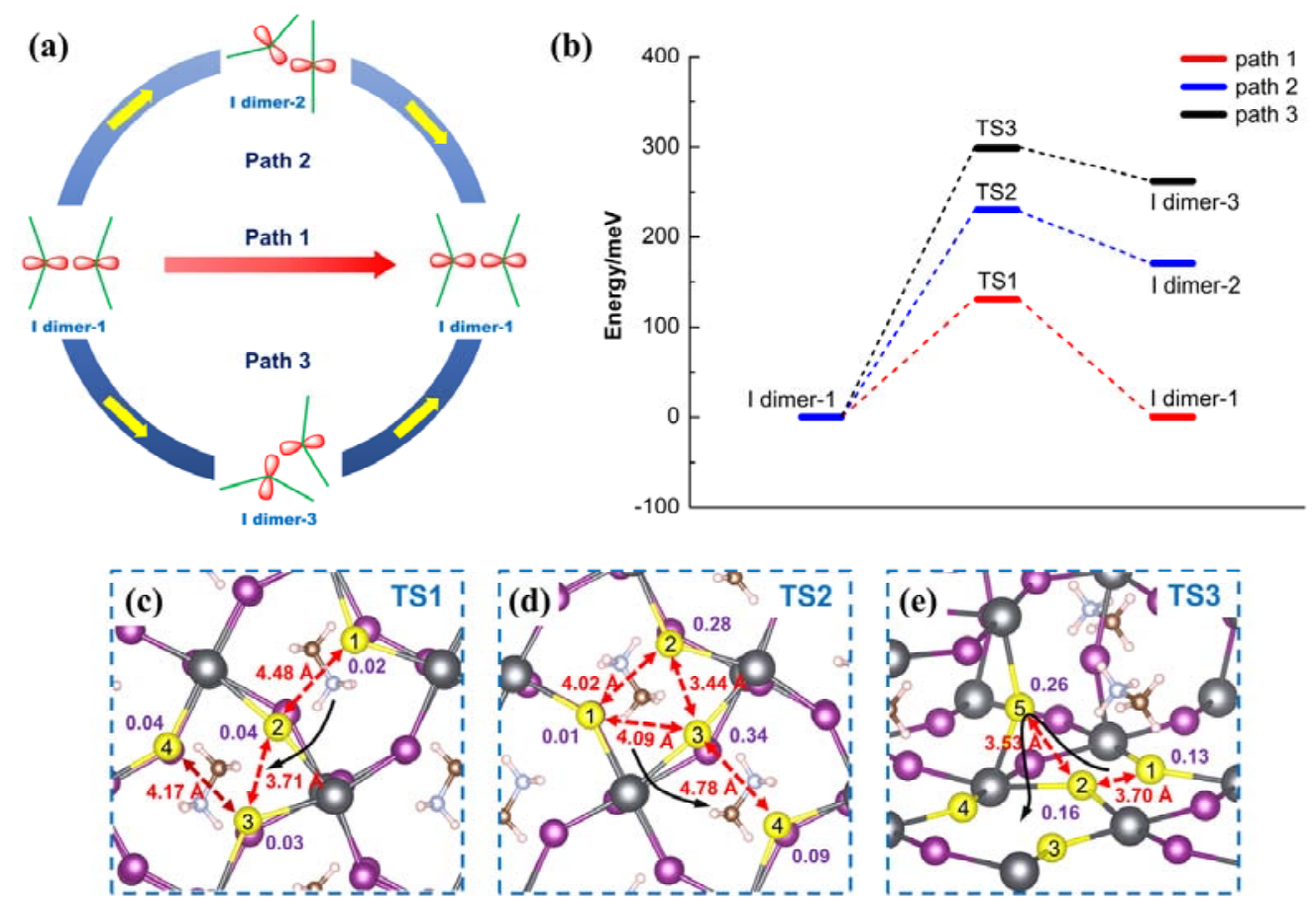

Figure 3. Paths and energy profile of the hole diffusion. (a) is the scheme for hole diffusion through three paths. (b) shows the energy profile of the three paths. (c) $\sim(e)$ are structures of the transition states in the three paths. The highlighted yellow 1, 2, 3, 4 and 5 balls are defined as the $\mathrm{I}^{1}, \mathrm{I}^{2}, \mathrm{I}^{3}, \mathrm{I}^{4}$ and $\mathrm{I}^{5}$ anions, respectively. The blue numbers are the spin densities of I anions. The bond lengths between I anions are in red color. The diffusion direction is indicated by the black arrows.

Path 2 and 3 are stepwise mechanisms, and both need go through an intermediate state (dimer$1 \rightarrow$ dimer- $2 \rightarrow$ dimer- 1 ; dimer- $1 \rightarrow$ dimer- $3 \rightarrow$ dimer- 1 ). In terms of path 2 , the hole diffuses starts from the configuration of I dimer 1 with hole trapped on $\mathrm{I}^{1 /} \mathrm{I}^{2}$ (see Figure $3 \mathrm{~d}$ ). Then, the hole moves towards the $\mathrm{I}^{3}$ anion in the mid-perpendicular direction of $\mathrm{I}^{1}-\mathrm{I}^{2}$ and transports to the intermediate state of dimer-2 $\left(\mathrm{I}^{2} / \mathrm{I}^{3}\right)$. Finally, the hole diffuses from the dimer-2 site to another dimer-1 site $\left(\mathrm{I}^{3} / \mathrm{I}^{4}\right)$. Figure $3 \mathrm{c}$ shows the structure of the transition state (TS2) from the dimer-1 and dimer-2 $\left(\mathrm{I}^{1 / \mathrm{I}^{2}} \rightarrow \mathrm{I}^{2} / \mathrm{I}^{3}\right)$. The distance between $\mathrm{I}^{2}$ and $\mathrm{I}^{3}$ is shortened to $3.44 \AA$, and the $\mathrm{I}^{1}-\mathrm{I}^{2}$ bond length is 
activated to $4.02 \AA$ from the initial $3.33 \AA$. Besides, one can see that the hole is trapped with spin densities mainly localizing at the connecting atoms of $\mathrm{I}^{2}\left(0.28 \mu_{\mathrm{B}}\right)$ and $\mathrm{I}^{3}\left(0.34 \mu_{\mathrm{B}}\right)$. In path 3 , the hole migrates from the dimer- 1 with hole trapped on $\mathrm{I}^{1} / \mathrm{I}^{2}$ to dimer-3 $\left(\mathrm{I}^{2} / \mathrm{I}^{5}\right)$ through the interaction of the equatorial $\mathrm{I}^{2}$ and apical $\mathrm{I}^{5}$ atoms. Then, the hole can further diffuse in the inverse manner from dimer-3 $\left(\mathrm{I}^{2} / \mathrm{I}^{5}\right)$ to the neighbored dimer-1 site $\left(\mathrm{I}^{3} / \mathrm{I}^{4}\right)$. TS3 is the transition state of hole diffusion between the dimer-1 and dimer-3 $\left(\mathrm{I}^{1} / \mathrm{I}^{2} \rightarrow \mathrm{I}^{2} / \mathrm{I}^{5}\right.$, see Figure $\left.3 \mathrm{e}\right)$, in which the hole localizes on the $\mathrm{I}^{1}, \mathrm{I}^{2}$ and $\mathrm{I}^{5}$ with spin densities of $0.13 \mu_{\mathrm{B}}\left(\mathrm{I}^{1}\right), 0.16 \mu_{\mathrm{B}}\left(\mathrm{I}^{2}\right)$ and $0.26 \mu_{\mathrm{B}}\left(\mathrm{I}^{5}\right)$. The distances between the $\mathrm{I}^{1 / \mathrm{I}^{2}}$ and $\mathrm{I}^{2} / \mathrm{I}^{5}$ are 3.70 and $3.53 \AA$, respectively.

Figure $3 \mathrm{~b}$ shows the energy barriers of hole diffusion via these three paths, in which paths 2 and 3 illustrate only the barriers from the initial state (dimer-1) to the intermediate state (dimer-2; dimer-3). We can see that the barrier of the concerted path 1 is $131 \mathrm{meV}$, while the barriers of the first step in paths 2 and 3 are 230 and $299 \mathrm{meV}$, respectively. Therefore, path 1 is kinetically the most favorable route for the hole diffusion. It is worth noting that all the barriers for the hole diffusion here are much lower than other photovoltaic materials such as $\mathrm{TiO}_{2}($ about $500 \mathrm{meV}){ }^{25}$ From the geometrical structures, the hole moves from one dimer site to another one with small lattice distortion. The less energy required for structural relaxation and non-breaking of $\mathrm{Pb}$-I bonds lead to the low barriers. Thermodynamically, the small hole trapping capacity of I dimer indicates a shallow potential well for the hole trapping and this is highly beneficial to the hole mobility. This unusual model, therefore, may play an important role to promote the hole diffusion in the $\mathrm{CH}_{3} \mathrm{NH}_{3} \mathrm{PbI}_{3}$ perovskite.

Origin of I dimers. The I dimer configuration trapped by hole is determined by certain factors. Firstly, the composition of the valence band and large atomic radius of iodine are expected to create favorable condition for the formation of I dimers. The $\mathrm{VBM}$ of $\mathrm{CH}_{3} \mathrm{NH}_{3} \mathrm{PbI}_{3}$ is 
constituted mainly by the I-5p states, which indicates the trapping of holes to proceed over the I anions in the $\mathrm{PbI}_{3}{ }^{-}$sublattice; in addition, the large atomic radius of iodine leads to an I-I distance in the I dimer as long as $3.33 \AA$. This enables very small lattice distortion for the hole trapping in an I dimer configuration (see Figure 1b). Secondly, the I anion also promotes the formation of I dimers. If the hole was trapped on an $\mathrm{I}^{-}$anion, it would give rise to an I radical by breaking two $\mathrm{Pb}$-I bonds, which could not form due to its very unstable nature. Moreover, we also considered the $\mathrm{I}_{2}$ generation in the system with two holes involved $\left(\mathrm{CH}_{3} \mathrm{NH}_{3} \mathrm{PbI}_{3}+2 h^{+} \rightarrow \mathrm{CH}_{3} \mathrm{NH}_{3} \mathrm{PbI}_{3-2 \mathrm{x}}+\right.$ $\mathrm{I}_{2}$ ). It is found that the reaction corresponds to an energy cost as high as $964 \mathrm{meV}$ with four $\mathrm{Pb}$ I bonds breaking and one I-I bond formation. Thus, breaking $\mathrm{Pb}-\mathrm{I}$ bonds to produce an iodine oxide is thermodynamically unfavorable. Thirdly, the stability of I dimer-1 is associated with a small structural deformation energy ( $E_{\text {def }}$ ) for the hole trapped in $\mathrm{CH}_{3} \mathrm{NH}_{3} \mathrm{PbI}_{3}$, where $\mathrm{E}_{\text {def }}$ is the structural energy difference between the hole delocalized and localized configurations (see details in SI). The smaller structural deformation energy means the less energy required for the structural relaxation to stabilize the localized hole. In the ort- $\mathrm{CH}_{3} \mathrm{NH}_{3} \mathrm{PbI}_{3}$ perovskite, its hybrid organic-inorganic structure is much flexible with $\mathrm{Pb}$-I bonds around $3.40 \AA$. The long bond lengths of $\mathrm{Pb}-\mathrm{I}$ bonds and large atomic radius of $\mathrm{Pb}$ and $\mathrm{I}$ lead to weak bonding of $\mathrm{Pb}-\mathrm{I}$ bonds. When the hole is introduced, only a small structural deformation energy $(259 \mathrm{meV})$ is required to elongate the $\mathrm{Pb}-\mathrm{I}$ bonds to form an I dimer-1, thereby maintaining its stability.

To further understand our results, we altered the halogen of $\mathrm{CH}_{3} \mathrm{NH}_{3} \mathrm{PbI}_{3}$ to investigate the different structural deformation energies on the thermodynamic stability of dimer states. With replacing the I element by the $\mathrm{Br}$ and $\mathrm{Cl}$ (see the structures in Figure S2), the EHTC decreases from -191 (I dimer) to 406 ( $\mathrm{Br}$ dimer) and $930 \mathrm{meV}$ ( $\mathrm{Cl}$ dimer). The corresponding $\mathrm{E}_{\text {def }}$ of the $\mathrm{I}, \mathrm{Br}$ and $\mathrm{Cl}$ dimers are 259, 940 and $1597 \mathrm{meV}$, respectively. It can be identified a good linear relationship 
between the $E_{\text {def }}$ and $E_{\text {HTC }}\left(\mathrm{R}^{2}=0.98\right)$ as shown in Figure 4. The Edef decreases linearly with the rising of Eнтс. This good linear correlation can be understood in the light of different bonding of $\mathrm{Pb}-\mathrm{X}(\mathrm{X}=\mathrm{Cl}, \mathrm{Br}$ and $\mathrm{I})$ as follows. From $\mathrm{Cl}$ dimer to $\mathrm{I}$ dimer, the elongations of $\mathrm{Pb}-\mathrm{X}$ bonds are similar, which are $0.3,0.2$ and $0.2 \AA$, respectively. Whereas the bond energies reduce gradually from $\mathrm{Pb}-\mathrm{Cl}$ to $\mathrm{Pb}-\mathrm{I}$ bonds, leading to the decreasing structural deformation energies and improving hole trapping capacities from $\mathrm{Cl}$ to I dimers. From the correlation, we also found that excellent $\mathrm{CH}_{3} \mathrm{NH}_{3} \mathrm{PbX}_{3}$ perovskites for the hole diffusion mainly concentrates in the redder area of the background with weak hole trapping capacity (the shallow potential well) and small structural deformation energy.

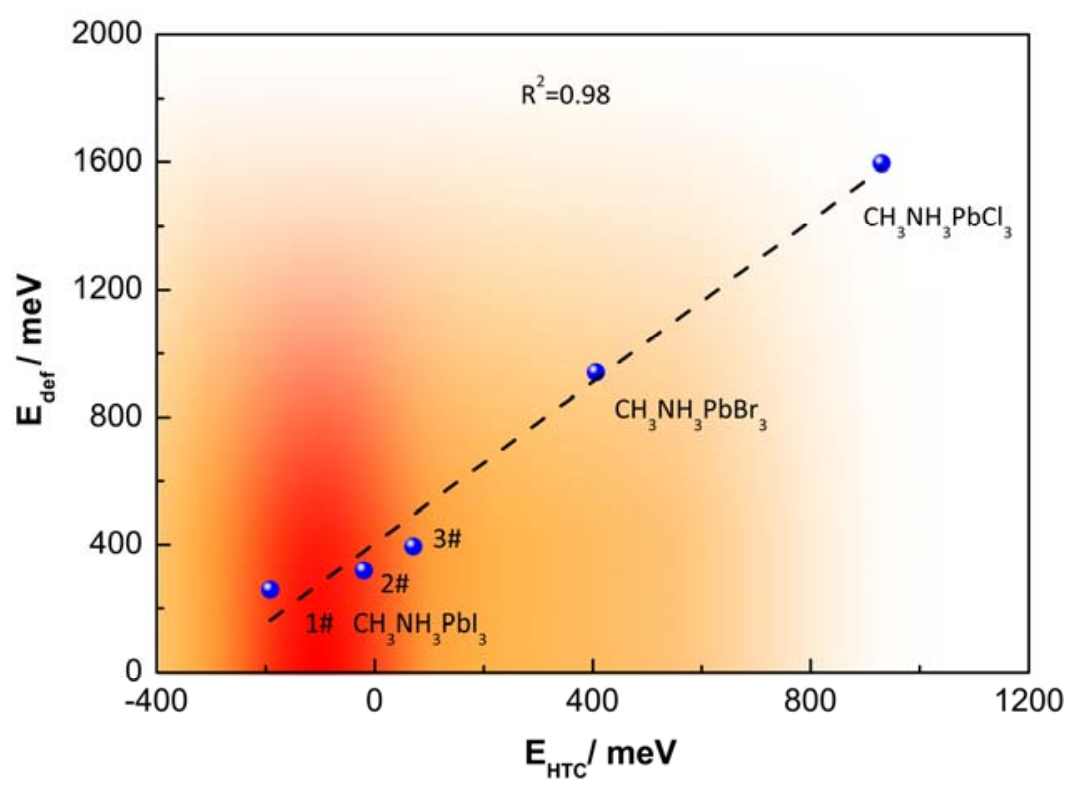

Figure 4. Linear relationship between the hole trapping capacities (ЕнтC) and the structural deformation energies $\left(E_{\text {def }}\right)$ from the dimers in the ort- $\mathrm{CH}_{3} \mathrm{NH}_{3} \mathrm{PbI}_{3}$ perovskite. 1\#, 2\# and 3\# represent the I dimer-1, dimer-2 and dimer-3, respectively. $\mathrm{R}^{2}$ is the square of the correlation coefficient. It is noted that, in contrast to $\mathrm{CH}_{3} \mathrm{NH}_{3} \mathrm{PbBr}_{3}$ and $\mathrm{CH}_{3} \mathrm{NH}_{3} \mathrm{PbCl}_{3}$, the excellent photovoltaic materials such as the $\mathrm{CH}_{3} \mathrm{NH}_{3} \mathrm{PbI}_{3}$ locate in the area with shallow EHTC and small Edef, 
which is approximately illustrated in the redder colored area (it is a rough indicator to show the good photovoltaic materials).

Uniqueness of I dimers. The representative anatase $\mathrm{TiO}_{2}$ bulk was investigated to uncover whether the dimer configuration is a general pattern in photovoltaic materials. Figure S3a illustrates the spin density distribution in the anatase $\mathrm{TiO}_{2}$ bulk with one hole involved. The hole is localized on one lattice oxygen site coupled with local structural distortion and forms an $\mathrm{O}^{*-}$ radical. The spin density of the $\mathrm{O}^{\circ}$ radical is $0.75 \mu \mathrm{B}$, and the corresponding Eнтc is $-296 \mathrm{meV}$, indicating the thermodynamically favorable formation of the $\mathrm{O}^{-}$radical in the system. Unfortunately, we cannot obtain an $\mathrm{O}$ dimer in the presence of one hole. It may result from the difficult generation of the unstable $\mathrm{O}_{2}{ }^{3-}$ species. With two holes involved, interestingly, $\mathrm{O}$ dimer emerges easily with $\mathrm{E}_{\mathrm{HTC}}$ of $-739 \mathrm{meV}$. The O-O distance in the dimer configuration is $1.52 \AA$ (see Figure S3b), and no spin density was found around these two O species. Those evidently indicate that there is an actual peroxide $(\mathrm{O}-\mathrm{O})^{2-}$ species formation in the system. In addition, we found another state that two holes are trapped on two separated lattice oxygen sites (see Figure S3c). The Ентс is $-447 \mathrm{meV}$. We can found that the $\mathrm{O}$ dimer is more stable than this state by $292 \mathrm{meV}$. It demonstrates the $\mathrm{O}$ dimer would consume more energy to activate the stable $\mathrm{O}-\mathrm{O}$ bond, and this is not beneficial to the hole transport. Therefore, the excellent diffusion of hole via dimers could be unique in the $\mathrm{CH}_{3} \mathrm{NH}_{3} \mathrm{PbI}_{3}$ perovskite.

In summary, in this work we systematically disclose the fundamental character and diffusion of photogenerated holes in the ort- $\mathrm{CH}_{3} \mathrm{NH}_{3} \mathrm{PbI}_{3}$ using high level first principles calculations. An unusual trapping state of the hole is identified for the first time, in which the photogenerated hole localizes as $\mathrm{I}_{2}^{-}$with a dimer configuration. This localized state is more stable than the hole delocalized state by $191 \mathrm{meV}$. The weak trapping capacity of the I dimer state highly promotes the 
hole diffusion with diffusion barrier as low as $131 \mathrm{meV}$. This is well consistent with the reported high mobility and long diffusion length of holes in the $\mathrm{CH}_{3} \mathrm{NH}_{3} \mathrm{PbI}_{3}$. Furthermore, the origin of I dimer is uncovered. We find that three major factors, the composition of valence band, the valence state of iodine anion and weak bonding between $\mathrm{Pb}$ and I, essentially determine the formation of I dimer. We demonstrate that the small structural deformation energy of the I dimer results in its unique character for the hole trapping and diffusion and that the excellent $\mathrm{CH}_{3} \mathrm{NH}_{3} \mathrm{PbX}_{3}$ perovskites are due to having small structural deformation energy and weak hole trapping capacity. The uniqueness analysis indicates I dimer is unique to promote the hole diffusion. It is expected that the insights obtained in this work may be crucial for understanding/improving the $\mathrm{CH}_{3} \mathrm{NH}_{3} \mathrm{PbI}_{3}$ perovskites in general.

Note added. During the revision of our paper, it has come to our attention that a paper of Kang et $\mathrm{al}^{\mathrm{x}}$ reporting an I dimer similar to I dimer-2 in our work in the tetragonal phase was accepted for

publication.

ASSOCIATED CONTENT

Supporting Information. The Supporting Information is available free of charge on the ACS Publications website at http://pubs.acs.org.

\section{AUTHOR INFORMATION}

\section{Corresponding Authors}

*p.hu@qub.ac.uk

*hfwang@ecust.edu.cn

\section{Notes}


The authors declare no competing financial interest.

\section{ACKNOWLEDGMENTS}

This project was supported by the National Natural Science Foundation of China (21333003, 21421004, 21622305), National Key Basic Research Program of China (2013CB933201), Young Elite Scientist Sponsorship Program by CAST (YESS20150131), “Shu Guang” project supported by Shanghai Municipal Education Commission and Shanghai Education Development Foundation (13SG30), and the Fundamental Research Funds for the Central Universities (WJ616007).

\section{REFERENCES}

(1) Kojima, A.; Teshima, K.; Shirai, Y.; Miyasaka, T. J. Am. Chem. Soc. 2009, 131, 60506051.

(2) Im, J.-H.; Lee, C.-R.; Lee, J.-W.; Park, S.-W.; Park, N.-G. Nanoscale 2011, 3, 4088-4093.

(3) Kim, H.-S.; Lee, C.-R.; Im, J.-H.; Lee, K.-B.; Moehl, T.; Marchioro, A.; Moon, S.-J.; Humphry-Baker, R.; Yum, J.-H.; Moser, J. E.; Graetzel, M.; Park, N.-G. Sci. Rep. 2012, 2, 591.

(4) Lee, M. M.; Teuscher, J.; Miyasaka, T.; Murakami, T. N.; Snaith, H. J. Science 2012, 338, 643-647.

(5) Etgar, L.; Gao, P.; Xue, Z.; Peng, Q.; Chandiran, A. K.; Liu, B.; Nazeeruddin, M. K.; Grätzel, M. J. Am. Chem. Soc. 2012, 134, 17396-17399.

(6) Stranks, S. D.; Eperon, G. E.; Grancini, G.; Menelaou, C.; Alcocer, M. J. P.; Leijtens, T.; Herz, L. M.; Petrozza, A.; Snaith, H. J. Science 2013, 342, 341-344. 
(7) Xing, G.; Mathews, N.; Sun, S.; Lim, S. S.; Lam, Y. M.; Graetzel, M.; Mhaisalkar, S.; Sum, T. C. Science 2013, 342, 344-347.

(8) Heo, J. H.; Im, S. H.; Noh, J. H.; Mandal, T. N.; Lim, C.-S.; Chang, J. A.; Lee, Y. H.; Kim, H.-j.; Sarkar, A.; Nazeeruddin, M. K.; Graetzel, M.; Seok, S. I. Nat. Photonics 2013, 7, 487-492.

(9) Liu, M.; Johnston, M. B.; Snaith, H. J. Nature 2013, 501, 395-398.

(10) Burschka, J.; Pellet, N.; Moon, S.-J.; Humphry-Baker, R.; Gao, P.; Nazeeruddin, M. K.; Graetzel, M. Nature 2013, 499, 316-319.

(11) Zhou, H.; Chen, Q.; Li, G.; Luo, S.; Song, T.-b.; Duan, H.-S.; Hong, Z.; You, J.; Liu, Y.; Yang, Y. Science 2014, 345, 542-546.

(12) Jeon, N. J.; Noh, J. H.; Yang, W. S.; Kim, Y. C.; Ryu, S.; Seo, J.; Seok, S. I. Nature 2015, $517,476-480$.

(13) De Wolf, S.; Holovsky, J.; Moon, S.-J.; Loeper, P.; Niesen, B.; Ledinsky, M.; Haug, F.-J.; Yum, J.-H.; Ballif, C. J. Phys. Chem. Lett. 2014, 5, 1035-1039.

(14) Yin, W.-J.; Yang, J.-H.; Kang, J.; Yan, Y.; Wei, S.-H. J. Mater. Chem. A 2015, 3, 89268942.

(15) Yin, W.-J.; Shi, T.; Yan, Y. Adv. Mater. 2014, 26, 4653-4658.

(16) Wehrenfennig, C.; Eperon, G. E.; Johnston, M. B.; Snaith, H. J.; Herz, L. M. Adv. Mater. 2014, 26, 1584-1589. 
(17) Ponseca, C. S., Jr.; Savenije, T. J.; Abdellah, M.; Zheng, K.; Yartsev, A.; Pascher, T.; Harlang, T.; Chabera, P.; Pullerits, T.; Stepanov, A.; Wolf, J.-P.; Sundstrom, V. J. Am. Chem. Soc. 2014, 136, 5189-5192.

(18) Feng, J.; Xiao, B. J. Phys. Chem. Lett. 2014, 5, 1278-1282.

(19) Umari, P.; Mosconi, E.; De Angelis, F. Sci. Rep. 2014, 4, 4467.

(20) Giorgi, G.; Fujisawa, J.; Segawa, H.; Yamashita, K. J. Phys. Chem. Lett. 2013, 4, 42134216.

(21) Even, J.; Pedesseau, L.; Jancu, J.-M.; Katan, C. J. Phys. Chem. Lett. 2013, 4, 2999-3005.

(22) Graetzel, M. Nat. Mater. 2014, 13, 838-842.

(23) Dong, Q.; Fang, Y.; Shao, Y.; Mulligan, P.; Qiu, J.; Cao, L.; Huang, J. Science 2015, 347, 967-970.

(24) Di Valentin, C.; Selloni, A. J. Phys. Chem. Lett. 2011, 2, 2223-2228.

(25) Deskins, N. A.; Dupuis, M. J. Phys. Chem. C 2009, 113, 346-358.

(26) Wu, X.; Trinh, M. T.; Niesner, D.; Zhu, H.; Norman, Z.; Owen, J. S.; Yaffe, O.; Kudisch, B. J.; Zhu, X. Y. J. Am. Chem. Soc. 2015, 137, 2089-2096.

(27) Ma, J.; Wang, L. W. Nano Lett. 2015, 15, 248-253.

(28) Frost, J. M.; Butler, K. T.; Brivio, F.; Hendon, C. H.; van Schilfgaarde, M.; Walsh, A. Nano Lett. 2014, 14, 2584-2590. 
(29) Buin, A.; Pietsch, P.; Xu, J.; Voznyy, O.; Ip, A. H.; Comin, R.; Sargent, E. H. Nano Lett. 2014, 14, 6281-6286.

(30) Haruyama, J.; Sodeyama, K.; Han, L.; Tateyama, Y. J. Am. Chem. Soc. 2015, 137, 1004810051.

(31) Eames, C.; Frost, J. M.; Barnes, P. R. F.; O'Regan, B. C.; Walsh, A.; Islam, M. S. Nat. Commun. 2015, 6, 7497.

(32) Li, W.; Liu, J.; Bai, F.-Q.; Zhang, H.-X.; Prezhdo, O. V. ACS Energy Lett. 2017, 2, 12701278.

(33) Mosconi, E.; Meggiolaro, D.; Snaith, H. J.; Stranks, S. D.; De Angelis, F. Energy Environ. Sci. 2016, 9, 3180-3187.

(34) Du, M. H. J. Phys. Chem. Lett. 2015, 6, 1461-1466.

(35) Neukirch, A. J.; Nie, W.; Blancon, J. C.; Appavoo, K.; Tsai, H.; Sfeir, M. Y.; Katan, C.; Pedesseau, L.; Even, J.; Crochet, J. J.; Gupta, G.; Mohite, A. D.; Tretiak, S. Nano Lett. 2016, 16, 3809-3816.

(36) Kresse, G.; Furthmüller, J. Comput. Mater. Sci. 1996, 6, 15-50.

(37) Kresse, G.; Hafner, J. Phys. Rev. B 1994, 49, 14251-14269.

(38) Menéndez-Proupin, E.; Palacios, P.; Wahnón, P.; Conesa, J. C. Phys. Rev. B 2014, 90, 045207.

(39) Adamo, C.; Barone, V. J. Chem. Phys. 1999, 110, 6158-6170. 
(40) Perdew, J. P.; Ernzerhof, M.; Burke, K. J. Chem. Phys. 1996, 105, 9982-9985.

(41) Giorgi, G.; Fujisawa, J.-I.; Segawa, H.; Yamashita, K. J. Phys. Chem. C 2014, 118, $12176-$ 12183.

(42) Amat, A.; Mosconi, E.; Ronca, E.; Quarti, C.; Umari, P.; Nazeeruddin, M. K.; Gratzel, M.; De Angelis, F. Nano Lett. 2014, 14, 3608-3616.

(43) Brivio, F.; Butler, K. T.; Walsh, A.; van Schilfgaarde, M. Phys. Rev. B 2014, 89, 155204.

(44) Kresse, G.; Joubert, D. Phys. Rev. B 1999, 59, 1758-1775.

(45) Blöchl, P. E.; Jepsen, O.; Andersen, O. K. Phys. Rev. B 1994, 49, 16223-16233.

(46) Alavi, A.; Hu, P.; Deutsch, T.; Silvestrelli, P. L.; Hutter, J. Phys. Rev. Lett. 1998, 80, 36503653.

(47) Peng, C.; Wang, H.; Hu, P. Phys. Chem. Chem. Phys. 2016, 18, 14495-14502.

(48) Zhang, J.; Peng, C.; Wang, H.; Hu, P. ACS Catal. 2017, 7, 2374-2380.

(49) Li, Y. H.; Peng, C.; Yang, S.; Wang, H. F.; Yang, H. G. J. Catal. 2015, 330, 120-128.

(50) Xing, J.; Wang, H. F.; Yang, C.; Wang, D.; Zhao, H. J.; Lu, G. Z.; Hu, P.; Yang, H. G. Angew. Chem. Int. Ed. 2012, 124, 3671-3675.

(51) Wang, H.-F.; Kavanagh, R.; Guo, Y.-L.; Guo, Y.; Lu, G.-Z.; Hu, P. Angew. Chem. Int. Ed. 2012, 51, 6657-6661.

(52) Wang, H. F.; Guo, Y. L.; Lu, G. Z.; Hu, P. Angew. Chem. Int. Ed. 2009, 48, 8289-8292.

(53) Grimme, S.; Ehrlich, S.; Goerigk, L. J. Comput. Chem. 2011, 32, 1456-1465. 
(54) Grimme, S.; Antony, J.; Ehrlich, S.; Krieg, H. J. Chem. Phys. 2010, 132, 154104.

(55) Geng, W.; Tong, C. J.; Liu, J.; Zhu, W.; Lau, W. M.; Liu, L. M. Sci. Rep. 2016, 6, 20131.

(56) Wang, Y.; Gould, T.; Dobson, J. F.; Zhang, H.; Yang, H.; Yao, X.; Zhao, H. Phys. Chem. Chem. Phys. 2014, 16, 1424-1429.

(57) Lang, L.; Yang, J.-H.; Liu, H.-R.; Xiang, H. J.; Gong, X. G. Phys. Lett. A 2014, 378, 290293.

(58) Brivio, F.; Walker, A. B.; Walsh, A. APL Mater. 2013, 1, 04211.

(59) Mosconi, E.; Amat, A.; Nazeeruddin, M. K.; Graetzel, M.; De Angelis, F. J. Phys. Chem. C 2013, 117, 13902-13913.

(60) Wang, D.; Wang, H.; Hu, P. Phys. Chem. Chem. Phys. 2015, 17, 1549-1555.

(61) Phuong, L. Q.; Yamada, Y.; Nagai, M.; Maruyama, N.; Wakamiya, A.; Kanemitsu, Y. J. Phys. Chem. Lett. 2016, 7, 2316-2321.

(62) Sendner, M.; Nayak, P. K.; Egger, D. A.; Beck, S.; Muller, C.; Epding, B.; Kowalsky, W.; Kronik, L.; Snaith, H. J.; Pucci, A.; Lovrincic, R. Mater. Horiz. 2016, 3, 613-620. 
Table of Content

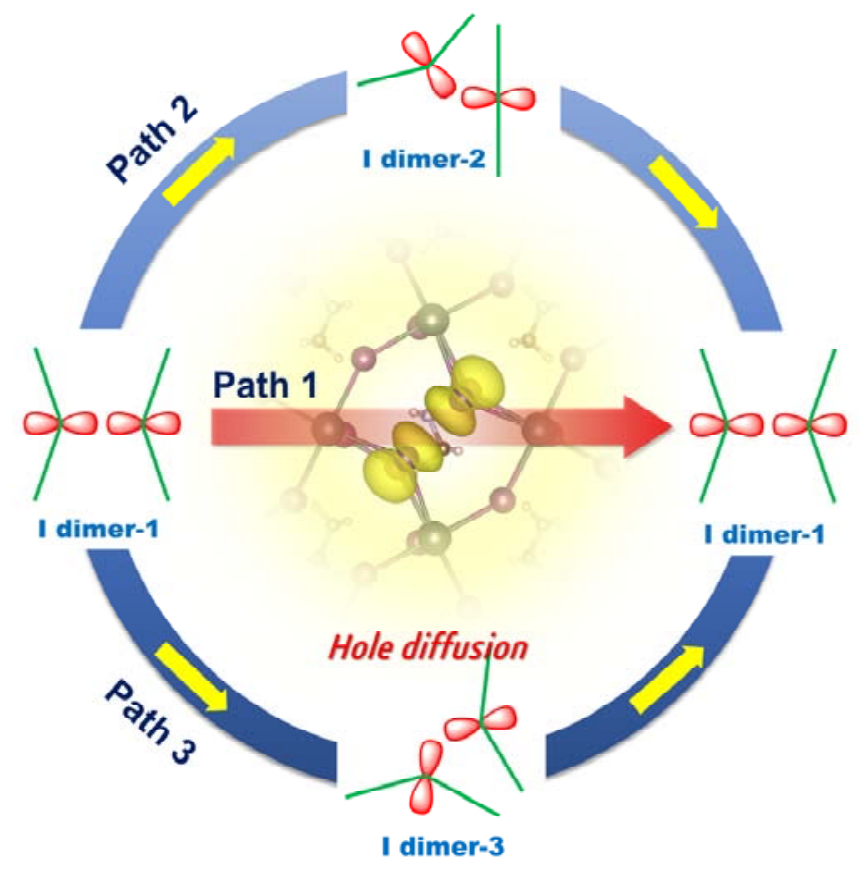

